Artigo Original

\title{
“O bicho, aquele pirralho" nos territórios indígenas colombianos: tecendo diálogos com a comunidade Kankuama em tempos de pandemia
}

\author{
"The bug, that little guy" in the Colombian indigenous territories: \\ Weaving dialogues with the Kankuama community in pandemic times
}

\section{"El bicho, ese chiquito" en los territorios indígenas colombianos: tejiendo diálogos con la comunidad Kankuama en tiempos de pandemia}

Viviana Marcela León Perilla ${ }^{a}$ (D), Lilian Magalhães ${ }^{\mathrm{a}}$ (D), Deina Krisned Corredor Pérez ${ }^{\mathrm{b}}$ (D), ${\text { Mariely Melissa Arias } \text { Olivero }^{\mathrm{b}} \text { (D), Brayan David Mamanché Cortes }}^{\mathrm{b}}$ (D),

Yidid Ramos Montero ${ }^{c}$ (D), Victor Segundo Arias Arias ${ }^{\mathrm{d}}$ (D), Diomedes Rafael Arias Arias ${ }^{\mathrm{d}}$

${ }^{a}$ Universidade Federal de São Carlos - UFSCar, São Carlos, SP, Brasil.

bUniversidad Nacional de Colombia - Unal, Bogotá, Colombia.

'Organización Nacional Indígena de Colombia - ONIC, Bogotá, Colombia

¿Organización Indígena Kankuama - OIK, Valledupar, Colombia.

Como citar: Perilla, V. M. L., Magalhães, L., Pérez, D. K. C., Olivero, M. M. A., Cortes, B. D. M., Montero, Y. R., Arias, V. S. A., \& Arias, D. R. A. (2021). "O bicho, aquele pirralho" nos territórios indígenas colombianos: tecendo diálogos com a comunidade Kankuama em tempos de pandemia. Cadernos Brasileiros de Terapia Ocupacional, 29, e2836. https://doi.org/10.1590/2526-8910.ctoAO2146

\begin{abstract}
Resumo
Este artigo tem como objetivo refletir sobre as experiências de afirmaçáo da vida e preparaçáo para a morte da comunidade colombiana indígena Kankuama, diante da pandemia e dos efeitos físicos, socioculturais, ecológicos e espirituais que fundamentam e impactam sua identidade, visibilidade, consciência e participação ocupacional. Por meio de pesquisa étniconacional colaborativa com base no pensamento indígena, o "Yarning" ou tecido foi utilizado para recuperar as narrativas de três kankuamos por meio de duas entrevistas semiestruturadas presenciais e uma virtual, gravadas e transcritas entre abril e agosto de 2020. As narrativas permitiram tecer reflexões vinculadas à luta pela preservação da própria dinâmica intercultural da saúde, reconhecendo elementos vinculados à sua história, além da ressignificação do vírus como fenômeno de aprendizagem do ser humano na relaçấo com a Mãe Terra e com o território. $\mathrm{O}$ artigo também aborda os processos ocupacionais vinculados à morte, enfatizando os aprendizados da perda e da consciência do legado espiritual dos mais velhos, decanos e sábios para a interpretação e orientação das práticas mortuárias da passagem ao "Chundwa". Resgatam-se as percepçóes que os Kankuamos possuem sobre a situação atual de saúde, conceitos de saúde e bem-estar, com base na Lei de Sé e sua relação com as
\end{abstract}


ocupaçôes relacionadas à morte, ao equilíbrio social, cultural e natural, que devem ser consideradas dentro da terapia ocupacional e da ciência ocupacional na América Latina.

Palavras-chave: Cultura Indígena, Infecçôes por vírus, Saúde Intercultural, Atitude Frente à Morte.

\section{Abstract}

This paper aims to reflect on the experiences involved in affirming life and preparing for the death of the indigenous Colombian Kankuama community, in the face of the pandemic and physical, sociocultural, ecological, and spiritual effects that underlie and impact their identity, visibility, awareness, and occupational participation. Through collaborative ethnic-national research based on indigenous thought, "Yarning" or fabric was used to recover the narratives of three kankuamos through two semi-structured face-to-face and one virtual interview, recorded and transcribed between April and August 2020. The narratives allowed to weave reflections linked to the struggle for the preservation of their intercultural health dynamics, recognizing elements linked to its history, the resignification of the virus as a phenomenon for the learning of humankind in the relationship with Mother Earth, and the land. The paper also addresses the occupational processes linked to death, emphasizing the learnings of the loss and awareness of the spiritual legacy of the elders, seniors, and sages for the interpretation and guidance of mortuary practices towards the "Chundwa". The Kankuamos' perceptions on the current health situation, health, and well-being concepts are presented, based on the "Ley de Sé" and its relationship with death-related occupations related to social, cultural, and natural equilibrium, which must be considered within occupational therapy and occupational science in Latin America.

Keywords: Indigenous Culture, Virus Infections, Intercultural Health, Attitude to Death.

\section{Resumen}

Este artículo tiene como objetivo reflexionar sobre las experiencias de afirmación de vida y preparación para la muerte de la comunidad indígena Kankuama colombiana, frente a la pandemia y los efectos físicos, socioculturales, ecológicos y espirituales que subyacen e impactan en su identidad, visibilidad, conciencia y participación ocupacional. A través de investigaciones colaborativas étnico-nacionales basadas en el pensamiento indígena, se utilizó "Yarning" o tejido para recuperar las narrativas de tres kankuamos a través de dos entrevistas cara a cara semiestructuradas y una virtual, grabadas y transcritas entre abril y agosto de 2020 . Las narrativas permitieron reflexiones vinculadas a la lucha por la preservación de la propia dinámica intercultural de la salud, reconociendo elementos vinculados a su historia, la resignificación del virus como fenómeno del aprendizaje del hombre en la relación con la Madre Tierra y el territorio. El artículo también aborda los procesos ocupacionales vinculados a la muerte, enfatizando las lecciones aprendidas de la pérdida y conciencia del legado espiritual de los ancianos, los mayores y los sabios para la interpretación y orientación de las prácticas mortuorias para el mundo "chundwa". Se recuperan las percepciones de los Kankuamos sobre la situación de salud actual, conceptos de salud y bienestar, a partir de la Ley de Sé y su relación con ocupaciones relacionadas con la muerte, el equilibrio social, cultural y natural, que deben ser considerados dentro de la terapia ocupacional y la ciencia de la ocupación en América Latina.

Palabras clave: Cultura Indígena, Infecciones por virus, Salud intercultural, Actitud Frente a la Muerte. 


\section{Introduçáo}

"O grão na espiga se acomoda e não luta para ocupar todo o espaço, a resistência na batalha nos faz conscientes de nos prepararmos para a liberdade espiritual e não ficarmos submissos à escravidão e ao sofrimento devido aos apegos ao mundo material" (Mensagem para os povos originários, dos Pais Espirituais durante a pandemia, Organización Nacional Indígena de Colombia, 2020).

Durante o mês de julho de 2020, a pandemia na Colômbia apresentou, após seis meses de disseminação, o maior pico de concentração com um surto letal que deixou 7.691 casos positivos e 272 mortes em comunidades indígenas, apresentando 55 novos casos diários e com duplicação dos casos a cada 10 dias. A evolução dos níveis de risco espacial de contágio mostra que a cada vez e gradativamente o número de comunidades indígenas que se encontram em baixo ou moderado risco passa a uma condição de maior probabilidade de contágio, exposta a afetar suas vidas, estimando 464 mortes a médio prazo devido ao vírus (Organización Nacional Indígena de Colombia, 2020). No texto o vírus será referido da mesma forma que as comunidades indígenas colombianas o chamam: "o bicho" nas orientaçóes dos Mamos (autoridades espirituais e políticas tradicionais) e Sagas (esposas e conselheiras dos Mamos), razão pela qual não será feita referência ao nome científico do vírus ao longo do artigo.

\section{Antes do bicho chegar nas comunidades indígenas colombianas}

Antes da pandemia, a situação de saúde e o perfil epidemiológico dos povos indígenas da Colômbia apresentavam diferenças em relação à situação geral de saúde do restante da população, manifestando-se em indicadores desfavoráveis em termos de mortalidade e morbidade (Buitrago, 2012). A incidência de doenças crônicas e transmissíveis decorrentes de processos de violação territorial, exclusão étnica, contaminação ambiental, conflito político e armado (Del Popolo et al., 2014; Bacigalupo et al., 2019) têm impactado não apenas a matriz biológica, mas cultural, espiritual e ocupacional de sua visão de mundo e bem-estar. Os povos indígenas colombianos vivem um duplo fenômeno de etnocídio, além da violência acentuada pelo controle do território indígena, com o aumento do deslocamento forçado de comunidades e o número de assassinatos de seus líderes (Ávila \& Guereña, 2020). Também enfrentam um inimigo invisível que, sem balas de fogo, coloca em risco o legado da nação e os guardióes da ancestralidade, devido à marcada mortalidade a partir dos 60 anos (correspondendo a 68,5\% das mortes), o que representa uma perda significativa para os povos indígenas. Considere-se que os Sábios (as), Anciãos (as) e Idosos (as) ${ }^{1}$ são os responsáveis por transmitir o conhecimento milenar de geração em geração (Organización Nacional Indígena de Colombia, 2020).

Como o milho, como os povos indigenas temos resistidos a mil batalhas para sobreviver? (Mensagem para os povos originários dos Pais Espirituais durante a pandemia (Organización Nacional Indígena de Colombia, 2020).

\footnotetext{
${ }^{1}$ A Organização Indígena Colombiana os denomina na versão feminina e masculina, pelo que será usado assim no desenvolvimento do artigo.
} 
As profundas dissonâncias culturais historicamente construídas entre crenças indígenas e não indígenas em relação à morte, gestão de doenças, saúde e cuidados médicos (Thompson et al., 2019) significam que a batalha atual não é apenas com o vírus em si. A crise da saúde reforçou as desigualdades sociais e as barreiras geográficas, econômicas e linguísticas ao acesso aos serviços básicos e de saúde mal integrados e diferentes na visão de mundo do cuidado, da saúde e da própria vida (Ávila \& Guereña, 2020).

São territórios que, carentes de uma infraestrutura de saúde adequada (Ratima et al., 2019), têm defendido o fortalecimento e a manutenção de seus conhecimentos e práticas baseadas na medicina tradicional para curar, socorrer e se despedir de seus irmãos e irmãs (Caballero, 2018), tendo em vista a Lei de Origem como conceito simbólico que tem norteado suas açôes em diferentes áreas (Fijal \& Beagan, 2019; Velez et al., 2020). Daí a convocação da Mãe Terra para identificar açóes próprias de cada povo como o uso de plantas e ervas, rituais familiares para evitar o encontro com muitas pessoas ao mesmo tempo, proteção espiritual para evitar desarmonias materiais e do pensamento, assim como o cuidado dos Anciōes e Anciãs para que se protejam e continuem suas atividades com cautela com o bicho (Organización Nacional Indígena de Colombia, 2020), são alguns exemplos da dinâmica dos serviços de saúde tradicionais em tempos de pandemia.

Compreendendo a importância da coletividade, da familiaridade e do território na transmissão de conhecimentos entre os povos indígenas da Serra Nevada de Santa Marta ${ }^{2}$ a aproximação com a comunidade Kankuama decorre do pertencimento de uma das autoras (MMAO) sendo ela originária da comunidade e residente do território sagrado na reserva localizada em Valledupar, no departamento de Cesar, território com uma população de 16.139 indígenas Kankuamos (Portal Único del Estado Colombiano, 2020); que registrou até o momento 360 casos de contágio dos 456 que ocorreram em indígenas da comunidade Kankuama devido ao bicho e 6 das 9 mortes (Organización Indígena Kankuama, 2020).

Levando em consideração que tanto a abordagem da morte quanto a vivência do luto podem ser um momento de grande importância na expressão das relaçóes humanas e do meio ambiente por meio da ocupação (Pollard, 2006), neste artigo pretendemos ouvir e dar voz às experiências envolvidas na afirmação da vida, bem como na preparação da morte a partir de um paradigma indígena sob uma perspectiva de descolonização (Bye, 1998; Essential \& McColl, 2019; Lucchi et al., 2020) no contexto de uma pandemia. Da mesma forma, propomos enfocar os processos ocupacionais que estão subjacentes, não a partir de uma visão colonial supostamente eurocêntrica (Hammell, 2020; Magalhães et al., 2018) e romantizada da boa morte, mas a partir de uma perspectiva étnico-nacional, retomando as experiências vividas pelos habitantes da comunidade Indígena Kankuama (Organización Indígena Kankuama, 2020). Será, assim, uma aposta para identificar, não só a perspectiva dessa comunidade sobre a trajetória de adoecer e morrer pelo vírus, mas também como essa construção permeia os laços com o seu meio social, cultural e ecológico em tempos de pandemia, por meio de uma primeira aproximação das raízes, da história particular da comunidade com suas múltiplas camadas de sensibilidades, persuasóes, pressupostos e escolhas vinculadas a este novo momento histórico (Trouillot, 2011). Portanto, náo pretendemos normalizar ou problematizar a própria perspectiva ocupacional ou projetar

\footnotetext{
${ }^{2}$ Os Kankuamos vivem no norte da Colômbia e habitam no topo da Sierra Nevada de Santa Marta, compartilhando cultura e tradiçáo com outros povos que coexistem, como os Kággaba (Koguis), os Iku (Arhuacos) e os Wiwa, estando dentro de sua cosmologia estes quatro povos como os guardióes do equilíbrio do mundo. Este território foi declarado pela UNESCO como Reserva da Biosfera e Patrimônio Mundial em 1979 devido à rede de ecossistemas que hospeda (Organização Indígena Kankuama, 2020).
} 
uma construção acadêmica dos determinantes do bem-estar, mas sim descrever essa busca de identidade e consciência ocupacional de sua saúde (Mahoney \& Kiraly-Alvarez, 2019). Saúde entendida como um processo que inclui determinantes vinculados ao contexto social, econômico, político, cultural e principalmente espiritual (Wilcock, 2006), na avaliação e sustentação de seus saberes ancestrais (Ramugondo et al., 2017) e na visibilidade da participação ocupacional que reflete sua forma cultural de saber, ser e fazer (Emery-Whittington \& Maro, 2018) em seus discursos locais frente ao bicho.

\section{Metodologia}

Este estudo é uma contemplação comunitária, uma reflexão configurativa inscrita no paradigma indígena ou ciência nativa, que privilegia os processos de descolonização e traços constitutivos (Daza, 2017; Rocha-Buelvas \& Ruíz-Lurduy, 2018; Smith, 2013) de três participantes indígenas selecionados da comunidade Kankuamo, frente aos seus sentimentos e vivências durante a atual pandemia, investigando a conexão desse novo cotidiano com suas práticas ancestrais, seus saberes e visão de mundo de saúde, doença e morte. Daza (2017) interpreta as ciências nativas como os processos de perceber, pensar, conhecer, agir e sistematizar a aprendizagem dos povos indígenas. Para Cajete (1999) o conceito de ciência nativa

[...] inclui espiritualidade, comunidade, criatividade e tecnologias para manter o meio ambiente e cuidar da vida humana, envolvendo aspectos como espaço e tempo, linguagem, pensamento e percepção, natureza e os sentimentos humanos, a relaçáo do ser humano com o cosmos e todos os aspectos revelados com a realidade natural (Cajete, 1999, p. 2).

\section{Participantes}

Os participantes foram convidados por suas abordagens profissionais ao contexto da educação, saúde e espiritualidade, tendo um importante papel -político, social e culturaldentro da comunidade como líderes do legado Kankuamo. Eles são:

Víctor Segundo Arias Arias, indígena Kankuamo, faz parte do conselho de anciãos (autoridades) da comunidade Kankuama de Chemesquemena e é etnoeducador da escola rural mista de Chemesquemena, segundo e terceiro anos do ensino fundamental, em favor da aprendizagem significativa e tradicional de seus alunos; pesquisador, músico e historiador das narrativas dos povos indígenas da Serra Nevada.

Yidid Ramos Montero, indígena Kankuama, coordenadora de saúde Kankuamos em Bogotá e responsável pelo Componente de Medicina Tradicional e Intercultural do plano de contingência da Organização Nacional Indígena da Colômbia. Ela recebe todas as recomendações, conselhos e conhecimentos dos Mayores (médicos tradicionais) do país, para divulgá-los nas comunidades indígenas.

Diomedes Rafael Arias Arias, indígena Kankuamo, professor de ciências sociais, atualmente ocupa o cargo de reitor da Instituição Educacional de Promoçáo Social Guatapurí-Chemesquemena, secretário do conselho de anciáos (autoridades) da comunidade Chemesquemena, músico tradicional, dirigente e pesquisador da língua Kankuama.

Ressalte-se que a comunidade Kankuama está organizada coletivamente para cumprir e respeitar os preceitos da Lei do Sé ou Lei de Origem. Assim, a voz de uma autoridade 
representa a voz de toda a comunidade, portanto o número de participantes não interfere na qualidade das informaçôes coletadas, conforme explicado por um dos participantes:

[...] Na nossa cosmovisão de indigena originário, temos uma lei de origem que é a que rege a ordem, de tal forma que não podemos sair dela porque é isso que está lá desde o inicio, todo o povo da comunidade vai te dizer a mesma coisa, ainda que seja em outras palavras, [...] não podemos mudar as coisas, não podemos mudar a ordem como fomos criados a partir do mundo ancestral (Victor).

\section{Geraçáo de dados}

Com base no respeito e na defesa da importância dos métodos de pesquisa indígenas, dentro de alianças colaborativas respeitosas com pesquisadores não indígenas (D’Antoine et al., 2019), esses membros da comunidade são reconhecidos como especialistas no sentido ético e epistêmico da pesquisa, em direção a uma ecologia dos saberes (Daza, 2017) que envolve os elementos e ferramentas que tradicionalmente têm ajudado a facilitar a aprendizagem, a compreensão do mundo e que fazem parte do cotidiano (Cajete, 1999).

Yarning (tecelagem $)^{3}$ é incorporado como um método qualitativo, prático e seguro de coleta de informaçóes, usando narrativas autóctones para alcançar uma compreensão respeitosa e culturalmente apropriada a partir de uma abordagem bidirecional e colaborativa. Os tecidos sendo a integração e a construção coletiva e recíproca a partir da troca de conversas no quadro da pesquisa narrativa, que retoma valiosos elementos históricos, valores, comportamentos e atitudes na experiência de vida do indivíduo indígena, que sejam relevantes para a pesquisa (Smith et al., 2020), relacionando-o com a interpretaçáo de tecido que a comunidade Kankuama possui que metaforiza

[...] tecendo o pensamento e fortalecendo a identidade cultural do povo, da família e dos valores ancestrais, bem como o conhecimento do princípio espiritual de coisas e situações (Vivas Sánchez, 2018, p. 22).

O Yarning tem o potencial de produzir achados e conclusóes que nem sempre são possíveis por meio de pesquisas tradicionais baseadas em arquivos e fontes empíricas (Osmond \& Phillips, 2019), permitindo o reconhecimento e incorporação de ontologias, epistemologias e axiologias indígenas (Barlo et al., 2020; Walker et al., 2012) que sustentam os saberes e modos de ser, fazer e pertencer da comunidade Kankuama frente à pandemia, resgatando as resiliências e potencialidades inerentes ao seu processo de cuidado holístico, ao invés de problematizá-las. Esse conhecimento pode trazer implicaçóes sociais e para a prática clínica visíveis entre as populaçóes indígenas como um importante complemento ao sistema de saúde e à abordagem biomédica (Bessarab \& Ng’andu, 2010; Dean, 2010; Geia et al., 2013).

Tendo em vista que as narrativas com a utilização desta metodologia se dáo como um processo interativo em diferentes momentos conversacionais de forma pessoal e direta (ver Figura 1), seu desenvolvimento foi resgatado e adaptado devido ao atual problema de saúde que não permite encontros presenciais. Focaliza-se o desenvolvimento da tecelagem com um caráter investigativo-

\footnotetext{
${ }^{3}$ Para o artigo vamos usar a palavra em portugues, respondendo ao interesse por produzir una investigaçáo apropriada ao contexto cultural e ao idioma usado pelos indígenas.
} 
colaborativo, destacando-se que a aproximação cultural de uma das autoras com a comunidade já assegurava o vínculo relacional / social com os participantes.

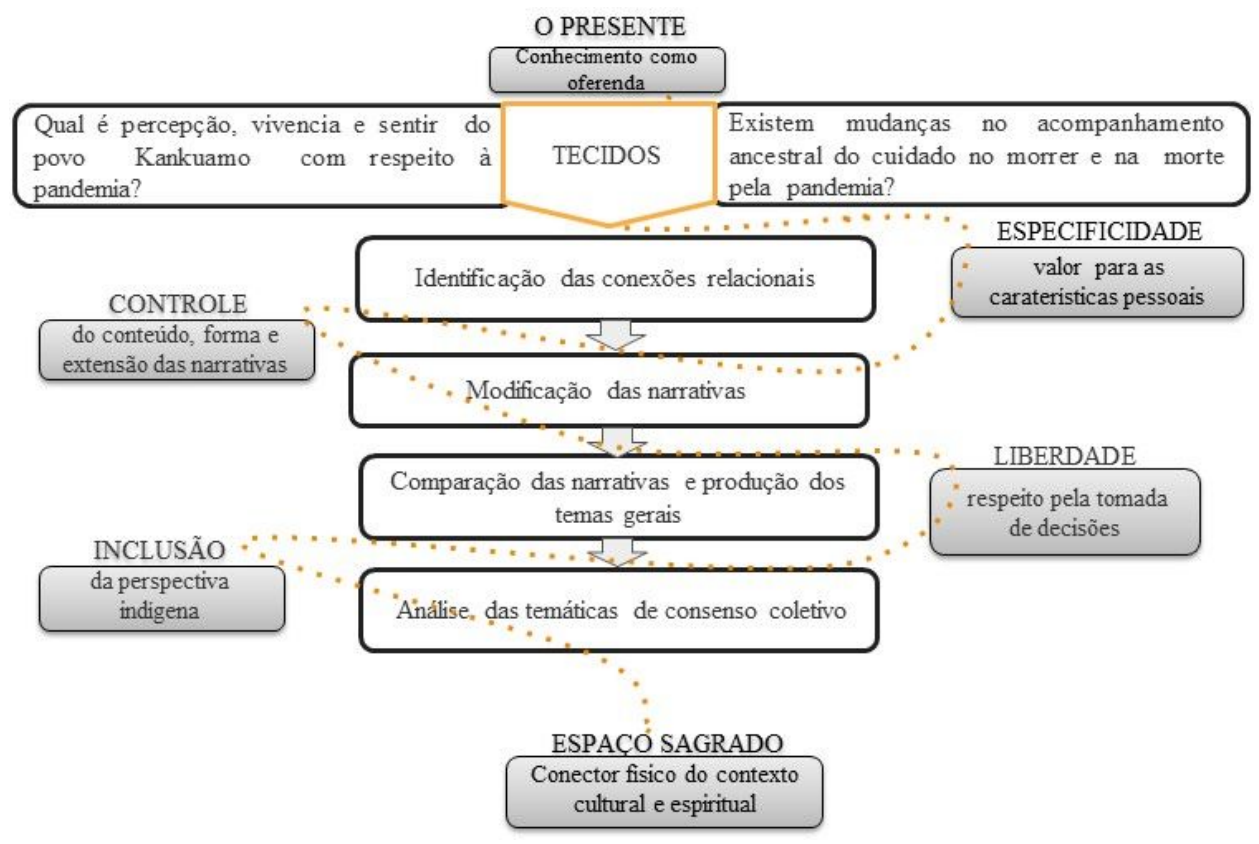

Figura 1. Tipo de tecidos. Fonte: Adaptado desde Bessarab \& Ng'andu (2010) e Dean (2010).

Assim, dois dos diálogos foram conduzidos pessoalmente (mantendo todos os protocolos de biossegurança) pela pesquisadora indígena pertencente à comunidade, por meio de entrevistas semiestruturadas que foram gravadas e transcritas pela mesma autora, obtendo-se duas narrativas iniciais. A outra entrevista foi realizada através da plataforma WhatsApp porque a participante não estava em sua comunidade no momento do convite. Nos três casos, o consentimento oral foi previamente aprovado pelo Cabildo Menor da comunidade Kankuama e pelos participantes, ocorrendo entre os meses de abril e agosto de 2020.

\section{Processo de Análise de Dados}

Após as entrevistas, todos os autores participaram da análise relacional colaborativa (Barlo et al., 2020) que foi dividida em quatro etapas:

1. Para identificar conexôes relacionais, as narrativas compartilhadas foram inicialmente separadas;

2. Cada participante foi consultado sobre as conexóes e descrições feitas a partir de sua narrativa original, de forma que fosse possível adicionar, remover ou modificar elementos dela.

3. As histórias de todos os participantes foram comparadas e integradas, produzindo um conjunto de temas vinculados às questôes norteadoras da pesquisa, sobre as quais os participantes foram consultados, iniciando-se de forma colaborativa as construçóes dos tecidos; 
4. Tanto os participantes quanto as pesquisadoras e pesquisadores vislumbraram a importância desses temas gerais ao longo do processo de construção dos tecidos, sem fazer julgamentos ou problematizá-los fora de seu contexto local.

A transmissão desse conhecimento foi uma dádiva que foi cuidada com detalhe ao longo de todo o processo, incorporando parâmetros éticos, culturalmente seguros e vinculados aos seus princípios para garantir aos participantes uma experiência recíproca, igualitária, responsável, digna e integrada à sua história, conhecimentos e memórias ligadas ao propósito da reunião (ver Figura 2). As narrativas nas cidades da Serra Nevada referem-se à transmissão de conhecimentos através da partilha da palavra, verbalizando fatos, histórias, mitos, contos e cançóes, que fazem parte da cultura das comunidades, com a particularidade de que estas narrativas deixam uma moral em quem as ouve. Como Victor, um dos participantes, se refere:

[...] Quando falamos de um tecido, não é apenas o tecido que se vê em qualquer objeto, mas o tecido do pensamento, que entre outras coisas nosso pensamento não é nem quadrado, não é retangular, mas tem a forma de um espiral, é cíclico, funciona, continua, assim como a Terra gira em torno do sol, em torno do universo, é assim que gira o nosso pensamento porque foi assim que nossos pais espirituais nos criaram [...] (Victor).

\section{Tecido Social}

$\dot{E}$ uma conversa anterior à investigação, é informal e muitas vezes desestruturada, segue um percurso sinuoso que se orienta pelo tema que as pessoas optam por introduzir na discussão, independentemente do rigor da informação, sendo noticias adequadas, humor, conselhos e qualquer informação que eles se sintam dispostos a compartilhar no momento, promovendo a porta de entrada para construir uma conexão da relação entre participantes e pesquisadores

\section{Tecido Investigativo}

É desenvolvido a partir de uma entrevista semiestruturada para coletar informações por meio das histórias dos participantes que se relacionam ao tema da pesquisa, com um propósito definido. Seu desenvolvimento é leve e interativo, mas também marca um começo e um fim definitivos

\section{Tecido Colaborativo}

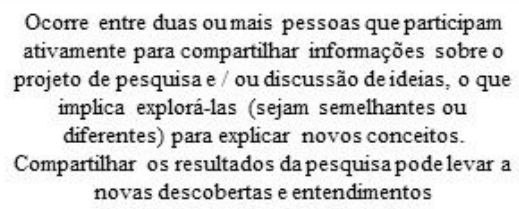

Ocorre entre duas ou mais pessoas que participam ativamente para compartilhar informações sobre o projeto de pesquisa e / ou discussão de ideias, o que implica explorá-las (sejam semelhantes ou diferentes) para explicar novos conceitos. Compartilhar os resultados da pesquisa pode levar a novas descobertas e entendimentos

\section{Tecido Terapêutico}

A história do participante revela informações traumáticas ou intensamente pessoais e emocionais. $O$ pesquisadorneste tipo de tecido fornece suporte ao participante para que sua história faça sentido e seja validada, Ao fazer isso, o significado emergente do tecido capacitará e apoiará o participante a reconsiderar sua compreensão da experiência de maneiras novas $e$ diferentes por meio de uma negociação conjunta

Figura 2. Interpretação metodológica da rota colaborativa para geração de dados baseada em Barlo et al.

(2020). Fonte: Realizado pelos autores a partir de Barlo et al. (2020).

\section{Resultados e Discussão}

Os participantes compartilharam aspectos de suas experiências durante a pandemia do bicho (Chiquito), por meio de diálogos que resgataram a atemporalidade do conhecimento 
e da conexão ancestral, forjando em conjunto dois tecidos tornados visíveis a partir da noção de saúde e da noção de morte pelo bicho. Todas as narrativas mantêm a originalidade do discurso, incluindo os termos originais, características suprassegmentais e sociolingüísticas ${ }^{4} \mathrm{da}$ comunidade indígena.

Assim, apresenta-se um primeiro tecido, denominado $A$ luta pela preservação da própria dinâmica intercultural da saúde em tempos de pandemia, no qual se evidencia o bicho como mensagem de aprendizado, conscientizaçáo e resistência, entendendo o impacto que tem gerado no território como um espaço físico de conexão espiritual e cultural. Esse processo está vinculado ao respeito e homenagem aos recursos da Máe Natureza como primeira instância de autocuidado diante da pandemia e suas implicaçóes nos processos interculturais projetados nas medidas preventivas de saúde tomadas localmente.

O segundo tecido denomina-se Respeito aos processos ocupacionais que implicam a morte de indígenas para além da pandemia, que contempla as reflexóes dos participantes sobre a morte em seu território como instância de afirmação da vida e ancestralidade, vista nos Rituais Funerários como o caminho da Mortuária para chegar ao mundo "Chundwa". Enfatiza-se o aprendizado que a pandemia proporcionou pela perda como a consciência do legado ancestral e a realização de adaptações das práticas ancestrais em torno do cuidado da morte pelo bicho.

\section{Primeiro tecido: A luta pela preservação de sua própria dinâmica intercultural de saúde em tempos de pandemia}

A saúde na visão de mundo das comunidades indígenas é dada por um equilíbrio ou harmonia da inter-relação da comunidade, a terra e as condiçóes físicas, emocionais, mentais e espirituais (Fijal \& Beagan, 2019). De maneira particular, a comunidade Kankuama possui seu próprio Modelo de Saúde Intercultural Kankuamo, no qual a saúde parte da Lei de Sé ou Lei de Origem, de uma visão integral que envolve especialmente o território, a natureza e a comunidade, levando a saúde para além do físico, para lhe atribuir propriedades coletivas e espirituais (Caballero, 2018). Segundo Wilcock (2006), esses próprios elementos culturais são determinantes subjacentes à saúde por meio do fazer. $\mathrm{Na}$ Comunidade Kankuama eles estáo presentes em todas as práticas, atividades e ocupaçóes tradicionais e ancestrais que os identificam.

A história da comunidade Kankuama mostra como outros determinantes da saúde propostos por Wilcock (2006), como mudanças no ecossistema [Mãe Terra] e interesses políticos e econômicos, têm gerado efeitos na saúde física, mental, emocional e espiritual da comunidade Kankuama. Estas são algumas das situaçóes que marcaram a sua história:

[...] Os espanhóis trouxeram muitos virus quando chegaram, variola era uma das coisas, febre amarela, depois vieram as doenças sexualmente transmissiveis [...] e éramos cem milhöes, cerca de 90 milhóes morreram naquela época, por isso é preciso obedecer e acatar as ordens de lá e de lá, bem como limpar-se e lavar-se [...] (Victor).

\footnotetext{
${ }^{4}$ As expressóes da regiáo onde vive essa comunidade indígena caracterizam-se pela retirada de algumas consoantes das palavras (respirao referindo-se ao respirado ou palla referindo-se para lá).
} 
Como povo, já sofremos muitas mortes por conta da pandemia da violência e agora esse virus silencioso nos acovarda a todos, tanto que a morte nesse sentido nos inquieta e nos faz pensar como vamos enfrentá-la (Yidid).

\section{Como Restrepo citado por Valtierra Zamudio \& Illicachi Guzñay (2019) menciona}

[...] a história é uma identidade que se forma e se transforma continuamente em relação às formas como somos representados ou desafiados nos sistemas culturais que nos cercam, porque a identidade é definida historicamente e não biologicamente (Valtierra Zamudio \& Illicachi Guzñay, 2019, p. 5).

A história faz parte da identidade cultural e coletiva de um povo, mostra os aprendizados e as lutas que o construíram, dando um sentido de coletividade, na interação com os outros e com o meio ambiente, em torno de realidades específicas sociais, políticas, culturais, econômicas, entre outras.

A ancestralidade é um elemento central na história e na vida da comunidade indígena Kankuama, pois é a partir do conhecimento dos ancestrais que o povo compreende as diversas realidades com que se depara e consegue ressignificar o pensamento a partir de suas experiências. Victor fala da atual emergência sanitária, como um acontecimento que também faz parte da vida da comunidade Kankuama e da compreensão que isso lhe proporcionou:

Esses ciclos se repetem sempre, a própria terra se cura, se limpa, o meio ambiente, o próprio meio ambiente se purifica [...] De vez em quando esses fenômenos vêm, a gente percebe como um conselho (Victor).

$\mathrm{O}$ vírus representa também um ciclo, ao qual a comunidade Kankuama deu um significado próprio e que tem uma missão na sua história; não representa apenas uma ameaça, mas em meio à dificuldade e às percepçóes negativas que enfrenta, eles encontram oportunidades para a Máe Terra se curar, bem como se fortalecer como uma comunidade. Dessa forma, Victor cria uma metáfora para o vírus, exemplificando com situaçóes cotidianas de seu interesse, a maneira como a própria essência do bicho se espalha como uma semente que dá origem à vida e por sua vez é aquela que se encarrega da própria natureza, para fazer a limpeza física, mental e espiritual de que você precisa:

Assim como muita coisa entra pelos olhos, aquela menina gordinha, aquele carro lindo entra pelos olhos, aquela comida que cheira gostosa entra pelo nariz [...] esse homem também entra pelo nariz, pela boca, também pelo que ele fala, ele está ouvindo o que eu falo aqui na serra [...] não ficar chamando tanto ele e até distrair, até na semente de batizado, quanto mais o Mamo fala, mais ele vem, mas ele está cumprindo a ordem que lhe é comandada. Esse pirralho tem uma história de origem, a vida nasceu assim, nasceu toda aquela semente da qual se fala negativo e positivo (Victor).

Aquela, aquele garotinho, que governa, a natureza já estava sufocada, doente! Quem adoece ?! Nós! Então ela, ela estava prestes a desmaiar e disse para si mesma: bom, aqui vamos fazer uma coisa Nós vamos limpar, então claro que não se para bolas, 
quem pensa que é governo não vai parar a bola, então mandam isso [...] (Victor referindo-se ao vírus como governo).

[...] vi também que as familias não iam se juntando, de repente, não tinha divisão na casa, às vezes ou, por exemplo, nas cidades eles nem sabiam fazer batata ou mandioca ou arroz, não, mesmo isso, Eles nem sabiam onde colocavam os vestidos, os cadernos das crianças; De modo que também na esfera social tem permitido de uma forma ou de outra que pessoas, mãe e pai, tio, sobrinho se encontrem, se encontrem e conversem sobre o seu cotidiano, sobre a vida, conhecer os gostos e desgostos dos filhos, das filhas, isso também permitiu que [...] permitiu a gente usar mais palavras, saudaçôes, carinho da palavra Como você acordou? Como você está? (Victor).

No entanto, é preciso reconhecer que Yidid se questiona e faz uma reflexão pessoal, que retoma a repercussáo e o acento que a disseminação do vírus traz consigo em termos principalmente socioeconômicos, pelo interesse que pessoas de fora dessas comunidades têm em aproveitar. de seus territórios para gerar riquezas pessoais que não beneficiam em nada seus habitantes, independentemente do risco de sua própria saúde, e até a própria vida, e turvando o valor cultural e espiritual do território, considerando-o apenas um recurso material do qual lucram e invisibilizando as lutas coletivas desse espaço (Garcia, 2013).

Antes de responder, gostaria de salientar que os povos indígenas da Colômbia acham que este virus é usado por estrangeiros como um negócio lucrativo [...] que se manifesta no medo geral de que o virus cause terror e paralisia da agenda dos Kankuamo, os Kankuamos estigmatizam que esse vírus vai nos matar e isso é o fim do mundo, não nos permitindo ver estratégias e dinâmicas de saida que fortaleçam a salvaguarda do povo Kankuamo (Yidid).

Inevitavelmente, o reconhecimento dos novos costumes do ser humano tem sido influenciado pela responsabilidade dos desenvolvimentos econômicos e políticas públicas que não garantem a redução das desigualdades, ou açóes sociais seguras em tempos de pandemia (Malfitano et al., 2020). Tanto a consciência ocupacional quanto as ocupaçóes descolonizadoras discutem como as ocupaçóes dos colonizadores são valorizadas e sua influência nas ocupaçóes das comunidades indígenas (Ramugondo et al., 2017; EmeryWhittington \& Maro, 2018) que implicaram em mudanças no meio ambiente e na perda de valores da comunidade. Victor exemplifica detalhadamente o impacto no mundo natural e no ecossistema, vinculado ao seu cotidiano:

[...] a natureza também sentiu calma com tanto alvoroço, tanto apito de carro, tanta fumaça de fábrica, fumaça de motocicleta, ela também conseguiu respirar e deu às plantas a oportunidade de processar e transformar aquele ar negativo em ar positivo [...] fez as pessoas pausarem, quanto mais aceleram, mais oxigênio consumimos, mais energia consumimos, isso também está desgastando a natureza, ou seja, tanta energia, tanta energia, não apenas eletricidade mas também a água, ela também foi limpa, 
deixou tanto sancocheo na margem do rio, o próprio mar, que dava para ver muito lixo e se limpou tudo com um sopro, a pausa tem servido [...] (Victor).

Assumir a responsabilidade de cuidar dos recursos naturais e dos espíritos que neles habitam precisa ser concebido como princípio básico para promover o equilíbrio e as relações ocupacionais com o ecossistema. Não se trata apenas de continuar a seguir os protocolos de biossegurança, como lavar as mãos, caso náo se tenha consciência do respeito pela água (Torres, 2020). Não há dúvida de que, para as comunidades indígenas, as ocupaçóes estão alinhadas com o mundo natural (Montaño, 2011). Para Víctor e Diomedes é fundamental resgatar, em tempos de pandemia, o ensino da natureza, para observar e compreender a verdadeira mensagem.

[...] fortalecer esse tipo de leitura, não só lendo livros, mas também lendo a natureza e encontrando as mensagens escondidas nas histórias, assim, tudo nasce de lá, Mamo sempre diz, busca a história, ai está todo conhecimento científico, isso também é conhecimento científico e a nossa obrigação é também interpretar, compreender, compreender e ouvir [...] (Victor).

[...] você sabe que para os Kogis é difícil chorar, isso de nós, que sim choramos, mas eles muito pouco. Mas olha, parecia muito forte e a própria natureza fala contra isso, então olha, mas aqui já, pelo mesmo tremor eu sei que vai sair que o tremor disse, forte, que a subida do rio Guatapuri disse no dia anterior, então isso, que seja consultado para definir-se bem o que aconteceu (Diomedes).

A pandemia parece ser um chamado para refletir sobre os modos de vida ocidentalizados e impositivamente apropriados, aos quais a comunidade foi comprometida pelo estilo de vida dos não indígenas. A recente transformação do cotidiano dos seres humanos devido ao isolamento e à falta de contato socioambiental (Malfitano et al., 2020) também cria uma nova oportunidade para as comunidades indígenas ratificarem a importância de suas práticas originais e conhecimentos ancestrais (Ávila \& Guereña, 2020).

Da mesma forma, o território tem um valor simbólico e espiritual, individual e coletivo para os povos indígenas, porque faz parte de sua identidade como pessoas e como povo, representa o que eles são e serão, conforme mencionam Bonnemaison \& Cambrézi citado por Kolling \& Silvestri (2019). Quando uma comunidade é despojada de seu território, existe o risco de que ela desapareça. No entanto, a atual situação de emergência de saúde acentuou de várias maneiras a desigualdade nos cuidados de saúde, particularmente nas áreas rurais e grupos populacionais vulneráveis, conforme expresso por Victor:

Também tem permitido aos animais resgatar um pouco o seu território, regressar ao seu território, ainda se lembram dos caminhos por onde trilharam os seus antepassados, por isso tem permitido que cheguem e visitem e também lembrem onde viveram e anseiam, anseiam aquela vida tão tranquila [...] (Victor).

Ao povo Kankuamo, diante dessa realidade devastadora, resta continuar se cuidando e prevenindo o vírus para evitar ao máximo o processo de mortes. Mas essa realidade também nos permite ter um panorama e antecipar estratégias que salvaguardem o direito ao luto, já

${ }^{5}$ Cerimônia espiritual, para limpar e reconhecer todos os elementos da natureza. 
que a relação entre o território e a vida das comunidades indígenas tem sido borrada, devido ao déficit estrutural que obriga as pessoas com o vírus a sair de seu território, e tem implicaçôes em um nível físico, social, espiritual e mental, conforme expresso por Victor e Yidid:

[...] eu tive a vivência da minha mãe, (silêncio prolongado) e ela se preparou, ela já estava atenta e disse para náo tirar ela do território dela, para náo levar pra morrer que ela viu que isso era uma tortura, ou seja, ela morreu com alegria porque estava aqui (Victor).

[...] as pessoas que entram no centro de saúde por outro motivo, nos casos de óbito, são tratadas como causa de morte pelo vírus. Isso implica que devemos nos preparar além de uma batalha legal para que entreguem o resultado do exame de virus, a certidão de óbito e o corpo não cremado [...] os Pais Espirituais indicaram isso quando uma pessoa nasce; $O$ umbigo e a placenta são semeados, da mesma forma, quando a pessoa morre, eles devem retornar ao ventre materno que garante o fortalecimento do território ancestral e fornece a força dos locais sagrados na linha negra, nossos corpos são o alimento dos pagamentos pois que nossos ancestrais nos guiem no futuro do Povo Kankuamo (Yidid).

Wilcock (citada por Rojas et al., 2011) afirma que a ocupação decorre da interação entre fazer com o ser e o tornar-se. Fazer refere-se às oportunidades ou restriçóes de um indivíduo ou coletivo que atendem aos seus interesses e, nessa medida, terá um impacto positivo ou negativo na saúde. Para o povo Kankuamo, o principal interesse, ou seja, tornar-se, é o equilíbrio entre a vida e a natureza, que se consegue através de várias práticas, principalmente de pagamento ${ }^{6}$, a este respeito Yidid comenta que ${ }^{7}$ :

[...] quando a pessoa morre, eles devem retornar ao ventre da mäe que garante o fortalecimento do território ancestral e proporciona a força dos locais sagrados na [...] é o alimento de pagamentos para que nossos antepassados nos guiem na vinda do Povo Kankuamo (Yidid).

Essas práticas também estão relacionadas a erros ou falhas para com a Divina Mãe Natureza e suas demandas, bem como ao não cumprimento das regras que nos permitem recuperar essa harmonia. Em relação a isso, Diomedes compartilha que:

[...] Será necessário, e se vier (a morte) é que no caso dos Kogis eles têm que fazer uma confissäo muito grande, grande isto é, consultar nos ezhuamas ${ }^{8}$ o que aconteceu, que fez com que aquela vida se perdesse e ver o que falhou, de repente houve falha de um Mamo porque ele não disse como tinha que se cuidar ou ele não cumpriu a ordem (Diomedes).

\footnotetext{
${ }^{6}$ Costume familiar de indígenas e não indígenas que prepara uma sopa de carnes, tubérculos, vegetais e condimentos na margem do rio.

${ }^{7}$ Exercício ancestral dos povos indígenas, nos quais pagamentos sáo feitos aos diferentes pais espirituais Espaço sagrado, que tem a função de ordenar e organizar os povos.

${ }^{8}$ Espaço sagrado para ordenar a vida dos seres
} 
[...] Você tem que coletar alguns elementos da natureza, elementos que são coletados nas lagoas principalmente e no mar para fazer isso, e ai, é feito como a limpeza disso, ai a gente começa a falar de todas as doenças que houve, ao limpar tudo isso, confessar, se é possivel confessar também por ele, o que fez a pessoa, isso também concerne à família (Fala Diomedes antes da morte do conselho governador do povo kogui José de los Santos Sauna).

A espiritualidade também identificada como a representação da verdadeira essência pessoal que conecta todos os seres vivos como expressão de sua natureza (Egan \& Delaat, 1994) está integrada à visão do território como uma linguagem espiritual e sagrada na comunidade, que está enraizada em todas as práticas ancestrais e atividades tradicionais; fortalecem a construção coletiva de crenças e valores com sentido de significado em cada membro ligado à natureza e ao universo (Tse et al., 2005). Em relaçáo aos elementos ligados à espiritualidade no processo de morte, Victor e Yidid compartilham que:

[...] onde a história fala que a gente vai para a Chundwa9 ${ }^{9}$, de onde sai, o Gonabindwa ${ }^{10}$ e passa para essa dimensão, para outra dimensão a dimensão espiritual, então isso nos permitiu refletir hoje (Victor).

A vida emocional, ainda que apenas uma pessoa morra do virus, causa desarmonia na população Kankuamo (Yidid).

No processo de garantir a saúde do povo Kankuamo a partir de todos os elementos mencionados acima, a Autoridade Nacional do Governo Indígena Colombiano com o objetivo de "contribuir para a oportuna e pertinente tomada de decisão das Autoridades Tradicionais, que atuam em Direito Próprio para a proteção de territórios e comunidades, bem como de organizaçóes sociais e étnicas" criou uma rede de apoio com entidades de cooperação e instituiçóes governamentais para concentrar esforços que garantam a continuidade da integridade dos 115 Povos Indígenas e Naçôes durante a pandemia (Organización Nacional Indígena de Colombia, 2020).

Portanto, o programa especializado de saúde se propôs a trabalhar e se adequar às necessidades dos povos indígenas, planos e serviços estaduais de saúde, bem como adequar a legislação nacional às necessidades e procedimentos culturais, incluindo a capacitaçáo dos próprios agentes de saúde, dados os problemas identificados como questôes de saúde, como a discriminação contra membros da comunidade indígena na prestação de serviços de saúde estaduais e a busca por conhecimentos médicos tradicionais. Desse modo, Victor e Yidid destacam a importância da continuidade da assistência à saúde como forma de prevenção do contágio e possível aumento de óbitos:

[...] tem permitido que você tenha mais cuidado com a higiene e isso é importante, e você tem que obedecer aquela regra, você sabe que é assim, então lave bem as mãos, se você olhar, você vê que quando você faz um serviço aqui num dos kankuruas ${ }^{11}$ costumava mandar ele lavar a mão para limpar e o sujo não permance (Victor).

\footnotetext{
${ }^{9}$ Lugar e espaço espiritual, onde se passa para a outra vida

${ }^{10}$ Montanha sagrada no sopé da Sierra Nevada

${ }^{11}$ Casa ceremonial Sagrada
} 
Ao povo Kankuamo, diante dessa realidade devastadora, só cabe continuar cuidando e prevenindo o virus para evitar o processo máximo de mortes. Mas esta realidade também nos permite ter um panorama e antecipar estratégias que salvaguardam o direito ao luto (Yidid).

A partir da orientação de pais espirituais para casos com sintomas leves, eles recomendam o uso de antibióticos naturais como alho, absinto, cebola, açafrão, eucalipto, orégano, alecrim, babosa, dente de leão, urtiga, unha de gato, equinácea, gengibre, limão, mel, própolis e vinagre de maçã (Organización Nacional Indígena de Colombia, 2020). Isso é expresso por Yidid e Diomedes já que esta medicina tradicional parte da Lei de origem, evitando ao máximo, o atendimento a centros médicos distantes de seus abrigos:

[...] tem comunidades que já tomaram a decisão de prevenir e tratar só com a medicina tradicional e não ir ao posto de saúde (Yidid).

Nesse momento, como eu te falei, não tinha ocorrido um caso desses, isso é uma novidade (denotou preocupação) então vai começar a consultar agora, primeiro o que aconteceu com aquela situação, segundo que será enfrentado aquele panorama porque os Mamos, o que eles pensam é como se muda como a metodologia que sempre existiu aqui, se está desde a origem [...] (Diomedes).

Quando os serviços são prestados em um contexto intercultural, é necessária uma compreensão profunda das crenças e desejos subjacentes das pessoas, suas visóes de mundo e seus relacionamentos humanos e não humanos como parte da compreensão de como os serviços podem responder a essas necessidades. Infelizmente, no nível epidemiológico, é reconhecido que o aumento das doenças crônicas e das taxas de mortalidade afetam mais a população indígena do que a não indígena (Shahid et al., 2018).

Aprender sobre saúde intercultural e sua indissociabilidade das condiçóes sociais (Hammell, 2020) é transversal à mensagem espiritual de todos os seres do mundo natural, história, território, natureza e espiritualidade como eixos centrais, preservando sua própria língua através do respeito e conservação das ocupaçóes ancestrais que garantam esse direito às próprias práticas de saúde, o que garante o cuidado de sua comunidade na vida e na morte.

\section{Segundo Tecido: Respeito pelos processos ocupacionais relacionados à morte de indígenas além da pandemia}

A morte pressupóe uma culminação inerente à existência humana, no caso das comunidades indígenas representa apenas a culminação da presença física no plano terreno de um mundo chamado terra, pois a partir daí começa uma nova vida, a qual é vivida apenas em um plano espiritual, como Yidid menciona:

Na vida espiritual do povo Kankuamo, a morte é percebida como o encontro do terreno com o espiritual, as cerimônias fúnebres têm grande valor de harmonia na relação entre o homem Kankuamo e a Divina Mãe Natureza (Yidid). 
Assim, antes disso, eles devem realizar uma série de atividades determinadas pela Lei de Origem, para iniciar uma vida espiritual plena quando a vida terrena terminar, na qual o cuidado da máe terra representa em grande parte uma parte fundamental deste processo de vida. Os cotidianos estáo relacionados ao projeto de vida da comunidade na qual as ocupaçóes estão intimamente relacionadas ao território. Diomedes exemplifica o aspecto acima e reflete sobre uma situação vivida:

Então veja, por exemplo, no caso do Sr. Juan e ele está aí, porque buscou-se fortemente os Mamos das bacias e eles contribuiram para que ele ainda pudesse resistir [...] ele se controlou mas não conseguiu mais, e ai ele tem que se resignar, porque justamente a morte também é vida, então há muito pensamos que não, que a morte é um desastre é uma coisa horrivel que não faz sentido, mas nós aqui na Sierra sim, porque ele vai continuar trabalhando a partir de lá [...] (Diomedes).

O exposto acima, nas palavras de Kolling \& Silvestri (2019, p. 213) refere-se a esse território como "um espaço de sobrevivência e reprodução de um povo, onde a cultura se realiza, onde o mundo foi criado, onde repousam os ancestrais", é um espaço sagrado onde a própria vida está ligada à terra e faz parte do ser; claro que são espaços onde ocorrem aspectos positivos e negativos e que devem ser remediados através do trabalho tradicional.

Esses trabalhos que a comunidade realiza como atividades de cura para apoiar quaisquer experiências de perda, dor e trauma, restabelecem as conexóes entre os tecidos naturais da vida humana e não humana. É através do ritual que o caminhar do espírito se conecta literal e metaforicamente, percorrendo o caminho e os espaços sagrados para representar, lembrar e apresentar sua vida terrena, permitindo nessas práticas ritualizadas incluir bens materiais e bens mais valorizados (Do Rozario, 1998). Diomedes detalha sua recente experiência no necrotério após o falecimento de um líder comunitário:

[...] Isso não mudou, nem vai mudar porque é assim desde o início, uma pessoa quando ela morre aqui passa para outra vida, para outro estado, e ai o que se faz é a morte, e a morte não é imediatamente, isso é consultado, aqui sempre se viu que tudo o que a pessoa deixou é recolbido, pensando em tudo o que ela fez, e depois os Mamos consultam quando pode ser feito o necrotério e alguns elementos que devem ser recolhidos são recolhidos, apanham-nos em diferentes partes do território, depois de apanhados, eles vêm, fazem o trabalho e começam a confessar tudo que aquela pessoa fez, como era, o que gostou, isso [...] é uma coisa que é delicada, a partir de amanhã é que vai ser consultado, já mandaram a mensagem de lá que tem que trabalhar 9 dias e 9 noites, e os trabalhos que vão ser feitos têm que ser novos, tem que começar a partir de agora (Suspiros e um tempo de silêncio olhando ao longe) [...] (Diomedes).

São os Mamos que facilitam esta interpretação da morte da pessoa e da influência no mundo terreno com as famílias e comunidades, além disso apoiam a passagem do irmão ao próximo nível espiritual denominado "Chundwa", como enfatiza Diomedes:

[...] O mortuário é importante porque ai nessa confissão os Mamos ajem como... eles escutam a mulher e aos filhos que são os mais compenetrados, então não acontece assim, isso, isso, entâo a ideia é consultar então você tem que trabalhar nisso para que ele chegue lá, digamos, que ele não chegue lá tâo afetado porque aqui já, digamos o 
estado de, aquele passa para a outra vida, aquele chega em um lugar aqui chamado "Chundwa", Chundwa é como se fosso o céu para nós, como aqui no Cristianismo que diz que vai para o céu então aqui vai para chundwa e ali em chundwa começa a outra vida (Diomedes).

Assim, a responsabilidade de ser Mamo ou Saga, entre tantas outras, prevalece o exemplo exercido a partir da experiência da pessoa, o seu papel de guia espiritual porque além de levar uma vida em harmonia com a Mãe Natureza, são eles que recebem as mensagens diretamente dos lugares sagrados, dos próprios pais espirituais e sáo encarregados de transmiti-las à comunidade, é a própria mãe quem recolhe as ações realizadas fora das diretrizes da Lei de Origem, que é exemplificada no que Diomedes mencionou:

[...] Nos casos dos Mamos, os idosos quase sempre morrem por um ato indevido que não deveriam fazer [...] espiritualidade aqui na Serra é bastante delicada, se um Mamo tem trabalhado em uma parte e deixa sua orientaçóes pode correr o risco de que ele morra, de que ele morra ou morra um parente próximo, com isso ele paga, que é uma forma de pagamento que a mãe lhe cobra, se ela não o deixar com uma situaçâo e ele não possa fazer mais nada (Diomedes).

O bem-estar social e emocional pode ser um conceito apropriado para usar quando se considera o papel, as responsabilidades e as ocupaçóes dos idosos e dos ancióes no processo de morrer. Seus papéis e responsabilidades refletem a importância de sua participação em ocupaçóes de luto e dor, à medida que continuam a transmitir conhecimentos à família e à comunidade. Por este motivo, a chegada do bicho aos povos Kankuamo tem reforçado a reflexão sobre o conhecimento do ciclo vital e a apropriação de conhecimentos em torno da não permanência no mundo terreno dos guardióes da sabedoria, cabendo às seguintes geraçóes diminuir as barreiras que impedem sua participação nas tarefas e responsabilidades do legado (Gibson, 2020). Isso pode ser visto no que Yidid mencionou:

A população mais vulnerável corresponde aos nossos velhos e anciōes, conhecedores dos conhecimentos ancestrais. O futuro do povo Kankuamo é incerto, uma vez que a força que temos na cultura e sabedoria ancestrais indígenas é perdida (Yidid).

Esses personagens são os membros mais estimados da cultura por todo o conhecimento cultural aplicado e são os guardiōes da sabedoria do legado, neles reside a confiança, a esperança e a continuidade do presente e do futuro das práticas ancestrais (Do Rozario, 1998). Levando em consideração os processos de adaptação ao vírus e suas implicações para a saúde, Yidid menciona que:

Nâo ter contato com o corpo é um bloqueio emocional que devemos sanar e harmonizar nâo só, mas com a ajuda dos idosos conhecedores da tradiçāo, pois uma estratégia de cura é enfrentar a realidade com visualização e contato (Yidid).

A consciência da morte parece envolver escolhas ocupacionais específicas, tanto para as pessoas que estão morrendo na comunidade quanto para as pessoas ao seu redor. Antes da pandemia, eles se prepararam para a própria morte, participando ativamente do 
acompanhamento da doença com práticas tradicionais e organizando rituais fúnebres. Como diz Pollard: "Embora morrer em si não possa ser visto como uma ocupação, é claro que as pessoas atribuem ao evento da morte um significado ocupacional intenso" (Pollard, 2006, p. 151). Em relação aos processos ocupacionais em torno da morte, Yidid e Victor compartilham que:

A vida social, pois as cerimônias fúnebres apesar dos sentimentos de dor e tristeza pela perda do ente querido, este momento em condiçôes normais permite o reencontro de irmãos e irmãs indígenas Kankuamos que por múltiplos motivos não puderam se ver, a reunião de familiares e amigos para apresentar condolências, para pôr em dia tudo o que aconteceu, mas hoje em meio ao vírus, a reuniáo social não é permitida, o abraço de solidariedade e condolências deixando um vazio e um gosto amargo nos parentes e até mais, nos enlutados (Yidid).

Isso é complicado, (silêncio) uma pessoa mesmo que ela não possa estar ali, digamos que você não pode estar, depois você tem que fazer isso com ela. O que mudou de repente é que no momento você não pode ficar com o cadáver, olha o que aconteceu com a Lúcia mesmo assim trouxeram ela aqui e foi feito velório [...] (Diomedes).

A importância das trocas simbólicas e materiais foram invisibilizadas por processos de homogeneização e poder, que tiveram uma influência importante na construção da identidade e, portanto, na perda de significado ocupacional (Trujillo et al., 2011). Os espaços de reflexão e companhia em torno da família na saída da pessoa supóem diálogos que fortaleçam os laços interculturais entre as famílias da Serra Nevada, Yidid afirma o seguinte:

$\mathrm{Na}$ vida política, se continuarmos a permitir que a morte mude suas cerimônias fúnebres devido ao contexto do virus, consideramos que estão em perigo a autonomia $e$ os exercícios de autogoverno que os indios Kankuamos têm (Yidid)

A reconexão entre a comunidade e suas propriedades tribais durante a pandemia é relevante para fortalecer suas ocupaçóes vinculadas aos processos de luto vinculados à expressão do real significado sobre a complexidade da relação entre as pessoas e o ambiente natural (McNeill, 2016).

\section{Consideraçóes Finais}

Os resultados desta pesquisa devem ser vistos como uma contribuição para a história e o diálogo intercultural, com o objetivo de aprofundar o entendimento das comunidades indígenas sobre a compreensão culturalmente adequada desta emergência sanitária por meio de abordagens a partir de seus sentires. Também diante das ocupaçóes como mediadoras dos encontros entre os sistemas sociocultural, espiritual e ecológico com o vírus. Além de tornar visível a gestáo territorial e a organizaçáo local como compromisso decolonial com os cuidados preventivos, curativos e paliativos.

Levando em consideração essa atitude ampla e holística em relação à saúde e ao bem viver, a terapia ocupacional pode aprender, apoiar e dar voz à dinâmica intercultural da saúde indígena colombiana por meio de novos tecidos colaborativos que favoreçam a 
identidade e a consciência ocupacional também do bom morrer, entendido a partir da atemporalidade, da harmonia e da ancestralidade dessas populaçóes.

\section{Liçóes aprendidas}

Deve-se notar que este estudo não representa as opiniōes de todos os indígenas colombianos. Foi um encontro enriquecedor que corresponde a um povo específico e a um momento específico, sendo relevante abordar a partir de uma aprendizagem coletiva e respeitosa as concepçóes ocupacionais indígenas de outras comunidades afetadas pela pandemia. O processo metodológico também foi afetado, sendo um desafio executar uma abordagem dinâmica com os participantes à distância e adotar uma postura de escuta e observação em todo o processo de desenvolvimento da pesquisa, fora de um espaço tangível e fisicamente concreto. Portanto, cada narrativa e construção dos tecidos foi respeitada e valorizada, identificando-se que se trata de uma primeira aproximação com a metodologia e a comunidade a partir da categoria profissional. Portanto, este não é um trabalho acabado, requer continuar a ser discutido e pensado sobre a transformação do vírus e os mecanismos de transmissão, os cuidados tradicionais adotados, bem como os parceiros locais e regionais de saúde para encontrar outros tecidos que podem ter escapado às percepçóes e aprendizagens dos pesquisadores.

\section{Agradecimentos}

Nosso reconhecimento especial à comunidade indígena Kankuama de La Sierra Nevada, Colômbia, por sua sobrevivência e resistência; especialmente às autoridades que participaram ativamente da construção deste artigo de pesquisa, ao Professor Victor Arias por compartilhar sua sabedoria, sua disposição e pelo compromisso iminente com a sobrevivência da comunidade. Ao Professor Diomedes Arias pela dedicação e por nos falar a partir da espiritualidade como ele próprio a expressa. À maioria Yidid pelas sábias palavras e conselhos sobre cuidados e prevenção a partir de um modelo intercultural. Todas as suas contribuiçóes foram essenciais para a análise e posteriores reflexôes que esperamos sejam de grande contribuição para a compreensão e execução de açôes voltadas ao atendimento do processo de final de vida em comunidades indígenas, a partir de suas visóes de mundo.

\section{Referências}

Ávila, R., \& Guereña, A. (2020). Evitar el Etnocidio: Pueblos indigenas y derechos territoriales en crisis frente a la COVID-19 en América Latina. Colombia: Oxaam International. Recuperado el 22 de julio del 2020, de https://oxfamilibrary.openrepository.com/bitstream/handle/10546/621028/bp-evitar-el-etnocidio210720-es.pdf?sequence $=1$.

Bacigalupo, J., Armada, F., \& Rigoli, F. (2019). Salud en clave decolonial: una perspectiva intercultural. Revista Salud Colectiva, S \& Derecho a la Vida, 1(1), 120-132. Recuperado el 5 de agosto del 2020, de http://biblioteca.clacso.edu.ar/clacso/se/20191105044046/RevistaSaludColectiva-JuLio2019.pdf\#page $=120$

Barlo, S., Boyd, W. E., Pelizzon, A., \& Wilson, S. (2020). Yarning as protected space: principles and protocols. AlterNative: An International Journal of Indigenous Peoples, 16(2), 90-98. http://dx.doi.org/10.1177/1177180120917480.

Bessarab, D., \& Ng'andu, B. (2010). Yarning about yarning as a legitimate method in indigenous research. International Journal of Critical Indigenous Studies, 3(1), 37-50. http://dx.doi.org/10.5204/ijcis.v3i1.57. 
Buitrago, N. (2012). Perfil epidemiológico de pueblos indígenas de Colombia. Colombia: Ministerio de Salud y Protección Social-Organización Panamericana de la Salud. Recuperado el 7 de agosto de 2020, de https://www.minsalud.gov.co/sites/rid/Lists/BibliotecaDigital/RIDE/VS/ED/perfil-epidemiologicoindigenas-parte2.pdf

Bye, R. A. (1998). When clients are dying: Occupational therapists' perspectives. The Occupational Therapy Journal of Research, 18(1), 3-24. http://dx.doi.org/10.1177/153944929801800101.

Caballero, N. (2018). Modelo de salud propio intercultural Kankuamo: autonomía politica indígena e interculturalidad en el pueblo indigena kankuamo de la sierra nevada de santa marta. Bogotá: Pontificia Universidad Javeriana. Recuperado el 15 de agosto de 2020, de https://repository.javeriana.edu.co/bitstream/handle/10554/46648/Modelo\%20de\%20Salud\%20Propio \%20Intercultural\%20Kankuamo\%20Nicol\%c3\%a1s\%20Caballero\%20Pineda\%202018II.pdf? sequence $=2 \&$ isAllowed $=y$

Cajete, G. (1999). Native science: natural laws of interdependence. Santa Fe: Clear Light Books.

D’Antoine, H., Abbott, P., Sherwood, J., Wright, M., Bond, C., Dowling, C., \& Bessarab, D. (2019). A collaborative yarn on qualitative health research with Aboriginal communities. Australian Indigenous Health Bulletin, 19(2), 1-7 Recuperado el 5 de agosto de 2020, de http://healthbulletin.org.au/articles/acollaborative-yarn-on-qualitative-health-research-with-aboriginal-communities/.

Daza, W. G. I. (2017). Epistemología pluralista, investigación y descolonización: aproximaciones al paradigma indígena. RevIISE: Revista de Ciencias Sociales y Humanas, 9(9), 111-125. Recuperado el de agosto de 2020, de http://www.ojs.unsj.edu.ar/index.php/reviise/article/view/131

Dean, C. (2010). A yarning place in narrative histories. History of Education Review, 39(2), 6-13. http://dx.doi.org/10.1108/08198691201000005.

Del Popolo, F., Jaspers, D., \& CEPAL, N. (2014). Los pueblos indigenas en América Latina. Avances en el último decenio y retos pendientes para la garantía de sus derechos. Santiago: NU. CEPAL. Recuperado el 16 de agosto del 2020, de https://www.cepal.org/es/publicaciones/37050-pueblos-indigenas-america-latinaavances-ultimo-decenio-retos-pendientes-la

Do Rozario, L. (1998). From ageing to sageing: Eldering and the art of being as occupation. Journal of Occupational Science, 5(3), 119-126. http://dx.doi.org/10.1080/14427591.1998.9686439.

Egan, M., \& Delaat, M. D. (1994). Considering spirituality in occupational therapy practice. Canadian Journal of Occupational Therapy, 61(2), 95-101. https://doi.org/10.1177/000841749406100205.

Emery-Whittington, I., \& Maro, B. T. (2018). Decolonising occupation: Causing social change to help our ancestors rest and our descendants thrive. New Zealand Journal of Occupational Therapy, 65(1), 12-19. Recuperado el 23 de agosto de 2020, de https://search.informit.com.au/documentSummary;dn=779745338782955;res=IELNZC

Essential, H. H., \& McColl, M. A. (2019). A model for occupation-based palliative care. Occupational Therapy in Health Care, 33(1), 108-123. https://doi.org/10.1080/07380577.2018.1544428.

Fijal, D., \& Beagan, B. (2019). Indigenous perspectives on health: integration with a Canadian model of practice. Canadian Journal of Occupational Therapy, 86(3), 220-231.

Garcia, S. (2013). El territorio como bases de una violencia espacial. Revista de Filosofía, 1(48), 37-48. Recuperado el 18 de agosto de 2020 de https://proyectoscio.ucv.es/wp-content/uploads/2014/06/03Susana-Garcia-Bujalance.pdf.

Geia, L. K., Hayes, B., \& Usher, K. (2013). Yarning/Aboriginal storytelling: towards an understanding of an Indigenous perspective and its implications for research practice. Contemporary Nurse, 46(1), 13-17. http://dx.doi.org/10.5172/conu.2013.46.1.13.

Gibson, C. (2020). When the river runs dry: Leadership, decolonisation and healing in occupational therapy. New Zealand Journal of Occupational Therapy, 67(1), 11-20. Recuperado 23 de agosto del 2020, de https://search.informit.com.au/documentSummary;dn=162982618221927;res=IELNZC.

Hammell, K.W. (2020). Action on the social determinants of health: Advancing occupational equity and occupational rights. Cadernos Brasileiros de Terapia Ocupacional, 28(1), 378-400. 
Kolling, P., \& Silvestri, M. (2019). Reflexões sobre território e terra indígena: aspectos culturais, sociais e jurídicos. Para Onde, 12(1), 211-226. http://dx.doi.org/10.22456/1982-0003.94569.

Lucchi, E., Caiata-Olgiati, G., Bonomi, M., \& Cembrani, F. (2020). Occupational therapy and palliative care. In C. Pozzi, A. Lanzoni, M. Graff \& A. Morandi (Eds.), Occupational Therapy for older people (pp. 125-144). São Paulo: Springer.

Magalhães, L., Farias, L., Rivas-Quarneti, N., Alvarez, L., \& Malfitano, A. P. S. (2018). The development of occupational science outside the Anglophone sphere: enacting global collaboration. Journal of Occupational Science, 26(2), 181-192. http://dx.doi.org/10.1080/14427591.2018.1530133.

Mahoney, W. J., \& Kiraly-Alvarez, A. F. (2019). Challenging the Status Quo: Infusing non-western ideas into occupational therapy education and practice. The Open Journal of Occupational Therapy, 7(3), 1-10. http://dx.doi.org/10.15453/2168-6408.1592.

Malfitano, A. P. S., Cruz, D. M. C., \& Lopes, R. E. (2020). Terapia ocupacional em tempos de pandemia: seguridade social e garantias de um cotidiano possível para todos. Cadernos Brasileiros de Terapia Ocupacional, 28(2), 401-404. http://dx.doi.org/10.4322/2526-8910.ctoED22802.

McNeill, H. N. (2016). Māori and the natural environment from an occupational justice perspective. Journal of Occupational Science, 24(1), 19-28. http://dx.doi.org/10.1080/14427591.2016.1245158.

Montaño, J. A. M. (2011). Ocupación como proceso ecológico. In A. T. Rojas, L. S. Camacho, L. C. Ferrer, E. P. Esquivel, S. R. Viscaya, J. U. Sarmiento, C. R. Castillo, L. P. Acevedo, \& J. A. M. Montaño. Ocupación: sentido, realización y libertad. Diálogos ocupacionales en torno al sujeto, la sociedad y el medio ambiente (pp. 130-150). Bogotá: Universidad Nacional de Colombia. Recuperado el 28 de julio de 2020, de https://repositorio.unal.edu.co/handle/unal/9033.

Organización Indígena Kankuama - OIK. (2020, Agosto 17). El Pueblo Kankuamo se declara en máxima alerta y reclama medidas urgentes y solidarias para su protección frente a la pandemia. Cabildo Indígena del Resguardo Kankuamo. Recuperado el 17 de agosto de 2020 de https://cabildokankuamo.org/elpueblo-kankuamo-se-declara-en-maxima-alerta-y-reclama-medidas-urgentes-y-solidarias-para-suproteccion-frente-a-la-pandemia/

Organización Nacional Indígena de Colombia - ONIC. (2020, Agosto 14). Boletín 046 sistema de monitoreo territorial (smt) - ONIC información para proteger la vida y los territorios. Recuperada el 20 de agosto de 2020, de https://www.onic.org.co/onic-salvando-vidas/4006-boletin-043-sistema-de-monitoreoterritorial-smt-onic-informacion-para-proteger-la-vida-y-los-territorio

Osmond, G., \& Phillips, M. G. (2019). Yarning about sport: indigenous research methodologies and transformative historical narratives. The International Journal of the History of Sport, 36 (13-14), 1271-1288. Recuperado el 18 de agosto de 2020, de https://www.tandfonline.com/doi/full/10.1080/09523367.2019.1691532.

Pollard, N. (2006). JOS Comment: Is dying an occupation? Journal of Occupational Science, 13(2-3), 149-152.

Portal Único del Estado Colombiano (2020). Datos Comisión Salud Pueblo Kankuamo. Comisión de Salud Propia e Intercultural. Recuperado el 22 de noviembre de 2020. de https://www.google.com/url?q=https:/www.datos.gov.co/Salud-y-Protecci-n-Social/Datos-Comisi-nSalud-Pueblo-Kankuamo/d6jb6fm3\&sa=D\&ust=1606332346111000\&usg=AOvVaw3iU02NB4Q0NFi2DU1LTSIl

Ramugondo, E., Lepere, R., \& Nebe, W. (2017). Decolonizing stigma and diagnosis as healing work. Health Tomorrow, 5, 1-23. Recuperada el 28 de agosto de 2020, de https://ht.journals.yorku.ca/index.php/ht/article/view/40246.

Ratima, M., Martin, D., Castleden, H., \& Delormier, T. (2019). Voces indígenas y sistemas de conocimiento: promover la salud del planeta, la equidad en salud y el desarrollo sostenible ahora y para las generaciones futuras. Global Health Promotion, 26(Supl. 3), 102-105.

http://dx.doi.org/10.1177/1757975919838730.

Rocha-Buelvas, A., \& Ruíz-Lurduy, R. (2018). Agendas de investigación indígena y decolonialidad. Izquierdas, (41), 184-197. Recuperado el 28 de julio de 2020, de https://scielo.conicyt.cl/scielo.php?script=sci_arttext\&pid=S0718-50492018000400184.

Rojas, A. T., Camacho, L. S., Ferrer, L. C., \& Esquivel, E. P. (2011). Compression de la Ocupación Humana. In A. T. Rojas, L. S. Camacho, L. C. Ferrer, E. P. Esquivel, S. R. Viscaya, J. U. Sarmiento, C. R. Castillo, L. P. Acevedo, \& J. A. M. Montaño. Ocupación: sentido, realización y libertad. Diálogos ocupacionales en torno al sujeto, la 
sociedad y el medio ambiente (pp. 27-71). Bogotá: Universidad Nacional de Colombia. Recuperado el 28 de julio de 2020, de https://repositorio.unal.edu.co/handle/unal/9033.

Shahid, S., Taylor, E. V., \& Cheetham, S. (2018). Key features of palliative care service delivery to Indigenous peoples in Australia, New Zealand, Canada and the United States: A comprehensive review. BMC Palliat Care, 17(72), 2018. http://dx.doi.org/10.1186/s12904-018-0325-1

Smith, L. T. (2013). Decolonizing methodologies: research and indigenous peoples. Nueva York: Zed Books Ltd.

Smith, R. L., Devine, S., \& Preston, R. (2020). Recommended methodologies to determine Australian Indigenous community members' perceptions of their health needs: A literature review. Australian Journal of Primary Health, 26(2), 95-103. Recuperado el 28 de julio de 2020, de https://www.publish.csiro.au/PY/PY19078.

Thompson, S., Lyford, M., Papertalk, L., \& Holloway, M. (2019). Passing on wisdom: exploring the end-oflife wishes of Aboriginal people from the Midwest of Western Australia. Rural and Remote Health, 19(4), 5444. http://dx.doi.org/10.22605/RRH5444.

Torres, M. A. (2020, Agosto 27). Tejiendo las estructuras desde el saber ancestral para el fortalecimiento de las prácticas ancestrales en salud. In II Foro Nacional Sistema de Salud Propia e InterCultural - SISPI: Componente Sabiduría Ancestral. Cesar, Colombia.

Trouillot, M. R. (2011). Moderno de otro modo: lecciones caribeñas desde el lugar del salvaje. Tabula Rasa, (14), 79-97. Recuperado el 20 de noviembre de 2020, de http://www.scielo.org.co/scielo.php?script=sci_abstract\&pid=S1794-24892011000100004n

Trujillo, R., Sanabria, L., Carrizosa, L., Parra, E., Rubio, S., \& Uribe, J. (2011). Ocupación: Sentido, realización y libertad. Diálogos ocupacionales en torno al sujeto, la sociedad y el medio ambiente. Colombia: Editorial Universidad Nacional de Colombia.

Tse, S., Lloyd, C., Petchkovsky, L., \& Manaia, W. (2005). Exploration of Australian and New Zealand indigenous people's spirituality and mental health. Australian Occupational Journal, 52(3), 181-187. http://dx.doi.org/10.1111/j.1440-1630.2005.00507.x.

Valtierra Zamudio, J., \& Illicachi Guzñay, J. (2019). La interculturalidad en la pastoral indígena: hacia un diálogo interreligioso en México, Guatemala y Ecuador. Instituto de Investigaciones en Ciencias Sociales y Humanidades, 30(2), 1-30. Recuperado el 15 de agosto de 2020, de https://www.researchgate.net/publication/339054722_La_interculturalidad_en_la_pastoral_indigena_ Hacia_un_dialogo_interreligioso_en_Mexico_Guatemala_y_Ecuador.

Velez, E. M. M., Rios, J. M. L., Marulanda, S. C., Franco, M. C. V., de La Rosa, O. D. M., \& Holguin, D. M. H. (2020). Approaching the concept of mental health for indigenous peoples in Colombia/Aproximación a la concepción de la salud mental para los pueblos indígenas de Colombia. Ciência \& Saúde Coletiva, 25(3), 1157-1167. Recuperado el 13 de agosto de 2020, de https://www.scielo.br/scielo.php?script=sci_arttext\&pid=S1413-81232020000301157

Vivas Sánchez, P. (2018). Memorias de la mochila indígena Kankuama: etnografía entre montañas (Tesis Trabajo de grado). Pontificia Universidad Javeriana, Bogotá. Recuperado el 20 de agosto de 2020, de https://repository.javeriana.edu.co/bitstream/handle/10554/35511/Memorias\%20de\%20la\%20mochila \%20ind\%c3\%adgena\%20Kankuama\%20Etnograf\%c3\%ada\%20entre\%20monta\%c3\%b1as.pdf?seque nce $=4 \&$ isAllowed $=y$.

Walker, M., Fredericks, B. L., \& Anderson, D. J. (2012). Understanding Indigenous Australian women's social and emotional wellbeing and wellness through yarning: The Indigenous Women's Wellness Program. Nueva Zelândia: New Zealand's Indigenous Centre of Research Excellence. Recuperado el 12 de agosto de 2020, de https://acquire.cqu.edu.au/articles/conference_contribution/Understanding_Indigenous_Australian_wo men_s_social_and_emotional_wellbeing_and_wellness_through_yarning_the_Indigenous_Women_s_ Wellness_Program/13459190/1.

Wilcock, A. (2006). Occupation: doing, healt and illness. In A. Wilcock. An occupational perspective of health (pp. 77-107). Thorofare: Slack Incorporated. 


\section{Contribuiçáo dos Autores}

Viviana Marcela León Perilla realizou a concepção, redação, organização das fontes e análise dos dados do texto. Deina Krisned Corredor Pérez e Brayan David Mamanché Cortes redigiram o texto, organização das fontes e análise dos dados, Mariely Melissa Arias Olivero fez a redação, coleta e análise dos dados. Lilian Magalhães orientou a condução do trabalho e revisão final do texto. Yidid Ramos Montero, Victor Segundo Arias Arias e Diomedes Rafael Arias Arias participaram da análise dos dados e aprovação do texto final. Todos os autores aprovaram a versão final do texto.

\section{Fonte de Financiamento}

O primeiro autor recebeu bolsa da Coordenação de Aperfeiçoamento de Pessoal de Nível Superior (CAPES), Brasil. Código: 001.

\section{Autora para correspondência}

Viviana Marcela León Perilla

e-mail: vivianaleonperilla.to@gmail.com

\section{Editora de seçáo}

Profa. Dra. Daniela Edelvis Testa 